$$
\text { Pontifícia Universidade C Católica }
$$

Tatiana de Mattos Kerber

Planejamento Experimental e Avaliação Metrológica da Produção de Lipases por Yarrowia lipolytica

Dissertação de Mestrado

Dissertação apresentada ao Programa de Pósgraduação em Metrologia para Qualidade e Inovação da PUC-Rio como requisito parcial para obtenção do título de Mestre em Metrologia.

Orientadora: Fatima Ventura Pereira Meirelles Co-orientadora: Gisela Maria Dellamora Ortiz 


$$
\operatorname{Pontifícia~}_{U_{\text {niversidade }} \text { Católica }_{\text {dio de Janeiro }}}
$$

Tatiana de Mattos Kerber

\title{
Planejamento Experimental e Avaliação Metrológica da Produção de Lipases por Yarrowia lipolytica
}

\begin{abstract}
Dissertação apresentada como requisito parcial para obtenção do grau de Mestre pelo Programa de Pós-graduação em Metrologia, Qualidade e Inovação do Centro Técnico Científico da Pontifícia Universidade Católica do Rio de Janeiro. Aprovada pela Comissão Examinadora e homologada pela Coordenação Setorial de Pós-Graduação, formalizado pelas respectivas assinaturas.
\end{abstract}

Comissão Examinadora:

Profa. Dra. Fatima Ventura Pereira Meirelles

Orientadora

Departamento de Química Pontifícia Universidade Católica do Rio de Janeiro (PUC-Rio)

Profa. Dra. Gisela Maria Dellamora Ortiz

Co-Orientadora

UFRJ - Faculdade de Fármacia

Profa. Dra. Elisabeth Costa Monteiro

Programa de Pós-Graduação em Metrologia (PósMQI)

Pontifícia Universidade Católica do Rio de Janeiro (PUC-Rio)

Prof. Dr. Ricardo Queiroz Aucélio Departamento de Química

Pontifícia Universidade Católica do Rio de Janeiro (PUC-Rio)

Prof. Dr. Edmar das Mercês Penha

EMBRAPA - Empresa Brasileira de Pesquisa Agropecuária

Prof. José Eugênio Leal

Coordenador Setorial de Pós-Graduação do

Centro Técnico Científico (PUC-Rio)

Rio de Janeiro, 18 de abril de 2007. 
Todos os direitos reservados. É proibida a reprodução total ou parcial do trabalho sem autorização da universidade, do autora e das orientadoras.

Tatiana de Mattos Kerber

Graduou-se em Química Industrial na PUC-Rio em 2004. Atua como Gerente da Qualidade do Laboratório de Caracterização de Fluidos do Departamento de Engenharia Mecânica da PUC-Rio.

Ficha Catalográfica

Kerber, Tatiana de Mattos

Planejamento experimental e avaliação metrológica da produção de lipases por Yarrowia lipolytica / Tatiana de Mattos Kerber ; orientadores: Fatima Ventura Pereira Meirelles, Gisela Maria Dellamora Ortiz. - 2007.

162 f. ; $30 \mathrm{~cm}$

Dissertação (Mestrado em Metrologia para a Qualidade e Inovação) - Pontifícia Universidade Católica do Rio de Janeiro, Rio de Janeiro, 2007.

Inclui referências bibliográficas.

1. Metrologia - Teses. 2. Biometrologia. 3. Lipase. 4. Yarrowia lipolytica. 5. Planejamento experimental. 6. D-optimal. 7. Incerteza de medição I. Pereira-Meirelles, Fatima Ventura. II. DellamoraOrtiz, Gisela Maria. III. Pontifícia Universidade Católica do Rio de Janeiro. Programa de PósGraduação em Metrologia para a Qualidade e Inovação. III. Título. 
Dedico este trabalho em primeiro lugar a Deus, sem o qual minha vida e tudo o que está a ela relacionado não teriam sentido, e aos meus avós, Almir e Maria Stella, pelo amor, carinho e atenção a mim dedicados ao longo dos saudosos anos em que convivemos juntos nesta vida. 


\section{Agradecimentos}

As minhas orientadoras, Fatima e Gisela, pela orientação, pelo apoio, pela competência científica e profissional transmitida e pela confiança em mim depositada.

A Fatima, um agradecimento especial, por ter sido mais do que orientadora, pela amizade, pelo carinho, pela paciência, pela constante atenção e principalmente pela dedicação e interesse na realização deste trabalho.

Ao meu querido Felipe, pelo seu amor, pela sua compreensão, por acreditar no meu potencial e por me ajudar a crescer como pessoa e como profissional.

A minha mãe, Fátima, e as minhas irmãs, Anna Karina e Suzana, pelo amor e carinho em todas as horas.

Aos meus sogros, Sérgio e Adelina, pelo apoio e incentivo de sempre.

Aos amigos Rosângela e Wanderley, os quais carinhosamente deram origem a toda essa caminhada.

Ao Professor Paulo Roberto de Souza Mendes pela valiosa contribuição no meu percurso desde a graduação.

Ao Professor Maurício Frota pelo apoio no decorrer do curso.

A Professora Paula Fernandes de Aguiar, do Instituto de Química da UFRJ, pelo auxílio nos cálculos e interpretação dos resultados.

À Márcia Ribeiro, secretária do Pós MQI/PUC - Rio, pela atenção e ajuda sempre que solicitada.

Aos funcionários do Laboratório de Biocorrosão e aos técnicos dos Laboratórios de Química Geral, Carlos e Charles, pela atenção e pelo empréstimo de alguns equipamentos utilizados neste trabalho.

Aos professores que participaram da Comissão Examinadora.

A todos os amigos e familiares que, de uma forma ou de outra, me estimularam a prosseguir trabalhando. 


\section{Resumo}

Kerber, Tatiana de Mattos; Pereira-Meirelles, Fatima Ventura; DellamoraOrtiz, Gisela Maria. Planejamento Experimental e Avaliação Metrológica da Produção de Lipases por Yarrowia lipolytica. Rio de Janeiro, 2007. 162p. Dissertação de Mestrado - Programa de Pós-Graduação em Metrologia. Área de concentração: Metrologia para Qualidade e Inovação (Pós-MQI), Pontifícia Universidade Católica do Rio de Janeiro.

Objetivo: Otimização da produção de lipases por células de Yarrowia lipolytica, através do planejamento experimental e avaliação dos aspectos metrológicos envolvidos no processo. Motivação: Embora existam muitos trabalhos na literatura que relatem a produção de lipases por microrganismos, poucos abordam a otimização do processo através do planejamento experimental e nenhum deles considera o rigor metrológico e a estimativa da incerteza de medição. Contextualização: As enzimas lipases serão objeto de estudo por apresentarem grande versatilidade de aplicações e por serem produzidas por muitos microrganismos. As leveduras, no entanto, apresentam inúmeras vantagens operacionais sobre os demais microrganismos e entre elas foi selecionada uma cultura de Yarrowia lipolytica, isolada no Brasil. A produção de lipases depende de muitas variáveis, como temperatura, $\mathrm{pH}$, concentração da fonte de carbono e nitrogênio, inóculo, entre outras. Nos processos de fermentação, onde há interação entre estas variáveis e a influência de cada uma é importante, é essencial estabelecer um método que considere estas interações, e otimize as condições experimentais para obtenção de melhores resultados. A confiabilidade metrológica do processo é de fundamental importância uma vez que diferenças significativas nos resultados são evidenciadas, principalmente em escala industrial. Metodologia: Dez experimentos foram planejados através do método D-optimal nos quais foram variadas as concentrações da fonte de carbono, da fonte de nitrogênio e de inóculo. A estimativa da incerteza de medição da atividade lipásica foi feita com base nas recomendações do Guia para Expressão da Incerteza de Medição (GUM) e do Guia CG 4 publicado pela EURACHEM. Resultados: A maior atividade lipásica obtida foi de 4815 U/L (80,3 $\mu \mathrm{kat} / \mathrm{L})$ com incerteza expandida de $137 \mathrm{U} / \mathrm{L}(2,3 \mu \mathrm{kat} / \mathrm{L})$, nas seguintes condições: 0,5\% de óleo de oliva (fonte de carbono), 0,7\% de peptona (fonte de nitrogênio) e $10 \mathrm{mg} / \mathrm{mL}$ de inóculo. Em termos de produtividade volumétrica, tais condições forneceram o valor de 69,28 U/L h. Conclusões: Com estes resultados, foi 
possível concluir que a utilização do planejamento D-optimal favoreceu a produção em agitador de frascos, já que foi atingida uma atividade lipásica superior às alcançadas anteriormente por outros autores sem otimização, em frascos agitados (2700 U/L) ou em fermentador (4240 U/L). Sugere-se a produção de lipases por células de Yarrowia lipolytica, nas condições citadas acima, com vistas à obtenção de materiais de referência certificados, desde que estudos posteriores de purificação e estabilidade da lipase obtida sejam feitos.

\section{Palavras-chave}

Biometrologia; Lipase; Yarrowia lipolytica; Planejamento experimental; Doptimal; Incerteza de medição. 


\section{Abstract}

Kerber, Tatiana de Mattos; Pereira-Meirelles, Fatima Ventura; DellamoraOrtiz, Gisela Maria. Experimental design and metrological evaluation of lipase production by Yarrowia lipolytica. Rio de Janeiro, 2007. 162p. M.Sc. Dissertation - Programa de Pós-Graduação em Metrologia. Área de concentração: Metrologia para Qualidade e Inovação (Pós-MQI), Pontifícia Universidade Católica do Rio de Janeiro.

Objective: Optimization of lipase production by Yarrowia lipolytica cells through experimental design and evaluation of metrological aspects related to process. Motivation: Although several published papers are found describing lipase production by microorganisms, few of them refer to process optimization through experimental design and none of them refer to metrological evaluation and the estimate of the uncertainty in measurement. Context: Microbial lipases are an important group of biotechnologically valuable enzymes that present widely diversified catalytic properties. The interest in production of these versatile enzymes increased significantly, due to the vast amplitude of their industrial applications. There are many microorganisms able to produce lipases, but yeasts present some operational advantages compared to other microorganisms, and for this reason a strain of Yarrowia lipolytica was used in this work. A serie of factors, individually or in association, can affect production of such substances leading to different levels of product concentration and productivity. Empirical studies have been traditionally used to determine the effect of these factors on process parameters. A possible approach is to vary one factor while keeping the other at a constant level, but this approach is time consuming, does not include the interaction effects among variables, and does not necessarily lead to optimized results. Nowadays, different strategies are employed to optimize production parameters. These strategies not only allow process optimization but can also establish the dependent and independent variables. Methodology: Ten experiments were planned with the D-optimal design in which concentrations of inoculum, carbon source and nitrogen source were changed. The estimate of the uncertainty in measurement of the lipase activity was developed based on the Guide to the Expression of Uncertainty in Measurement (GUM) and on the Guide CG 4 published by EURACHEM. Results: The highest lipolytic activity obtained was $4815 \mathrm{U} / \mathrm{L}(80,3 \mu \mathrm{kat} / \mathrm{L})$ with an expanded uncertainty of $137 \mathrm{U} / \mathrm{L}$ (2,3 $\mu \mathrm{kat} / \mathrm{L}$ ), under the following conditions: $0.5 \%$ of olive oil (carbon source), 
$0.7 \%$ of peptone (nitrogen source) and $10 \mathrm{mg} / \mathrm{mL}$ of inoculum. In terms of volumetric productivity, these conditions provided 69.28 U/L h. Conclusions: It is possible to conclude that the D-optimal design usage enhanced lipase production in shaken-flasks. Moreover the activity obtained in this work was higher than others previously reported with the same microorganism, without experimental design, in shaken-flasks (2700 U/L) or even in bench-fermenter (4240 U/L). The production of lipases by Yarrowia lipolytica cells aiming the classification as certified reference material can be recommended after further purification and stability studies.

\section{Keywords}

Biometrology; Lipase; Yarrowia lipolytica; Experimental design; D-optimal; Uncertainty in measurement. 


\section{Sumário}

1. Introdução: contexto e motivação

2. Conceitos teóricos e revisão bibliográfica 23

2.1. Conceitos metrológicos 23

2.2. Fundamentos de metrologia 28

2.2.1. Metrologia química 31

2.2.2. Biometrologia 33

2.2.3. Estimativa da incerteza de medição 37

2.2.3.1. Avaliação do Tipo A da incerteza padrão 39

2.2.3.2. Avaliação do Tipo B da incerteza padrão 39

2.2.3.3. Determinação da incerteza padrão combinada 40

2.2.3.4. Fator de abrangência e número de graus de liberdade 40 efetivos

2.2.3.5. Determinação da incerteza expandida 41

2.3. Células de Yarrowia lipolytica 41

2.4. Lipases 43

2.4.1. Definição, estrutura e características 43

2.4.2. Aplicações 45

2.4.3. Produção e purificação 50

2.4.3.1. Fermentação 52

2.4.3.2. Produção de lipases por Yarrowia lipolytica 55

2.4.3.3. Purificação 56

2.4.4. Detecção e medição da atividade lipásica 58

2.5. Planejamento experimental 62

3. Objetivos 66

3.1. Objetivos gerais 66

3.2. Objetivos específicos 66

4. Materiais e métodos $\quad 67$

$\begin{array}{ll}\text { 4.1. Materiais } & 67\end{array}$

$\begin{array}{ll}\text { 4.1.1. Vidrarias } & 67\end{array}$ 
4.2. Reagentes 69

4.3. Planejamento experimental 70

$\begin{array}{ll}\text { 4.4. Microrganismo } & 72\end{array}$

4.5. Meios de cultura $\quad 72$

4.5.1. Meios sólidos $\quad 72$

4.5.2. Meios líquidos $\quad 72$

4.6. Produção da enzima

4.7. Purificação do óleo de oliva 76

4.8. Determinação do índice de acidez do óleo de oliva 76

4.9. Métodos analíticos 76

4.9.1. Quantificação do crescimento celular 76

4.9.2. Determinação da atividade lipásica $\quad 77$

4.10. Estimativa da incerteza de medição da atividade lipásica 77

4.10.1. Incerteza padronizada da concentração em quantidade 79 de matéria da solução de $\mathrm{NaOH}$

4.10.2. Incerteza padronizada do volume de $\mathrm{NaOH}$ adicionado 81

4.10.3. Incerteza padronizada do tempo 82

4.10.4. Incerteza padronizada do volume de amostra 82

5. Resultados e discussão 83

5.1. Curvas de calibração das vidrarias 83

5.2. Avaliação da melhor metodologia para a obtenção das 84 repetições da quantificação do crescimento celular

5.3. Avaliação do número de repetições necessárias para 86 determinação da atividade lipásica

5.4. Perfis de crescimento celular e de atividade lipásica 86

5.5. Efeitos das concentrações iniciais da fonte de carbono, da 100 fonte de nitrogênio e do inóculo sobre a produção de lipases

5.6. Planejamento experimental para a produção de lipases de 104 Yarrowia lipolytica

5.7. Estimativa da incerteza de medição da atividade lipásica

6. Conclusões 
8. Referências bibliográficas

9. Apêndice 125

9.1. Certificados de calibração 125

9.2. Recomendações para calibração, verificação e manutenção de 151 equipamentos

9.2.1. Calibração e verificações de calibração 151

9.2.2. Verificação de desempenho 152

9.2.3. Manutenção 154

9.3. Curvas de calibração das vidrarias 156 


\section{Lista de Figuras}

Figura 2.1 - Estrutura Metrológica Internacional 29

Figura 2.2 - Hierarquia do Sistema Metrológico 30

Figura 2.3 - Esquema representativo da hierarquia de materiais de 37 referência para a transferência de exatidão nas medições de enzimas

Figura 2.4 - Reação da ação catalítica de lipases 43

Figura 2.5 - Representação esquemática das reações catalisadas 44 por lipases

Figura 2.6 - Estrutura da lipase de Pseudomonas aeruginosa

Figura 2.7 - Mecanismo de produção de lipases por células de Yarrowia lipolytica

Figura 4.1 - (a) Agitador de frascos utilizado em todos os cultivos.

(b) Frascos Erlenmeyers contendo os meios inoculados

Figura 4.2 - Diagrama do processo de produção de lipases

Figura 4.3 - Diagrama de causa e efeito com as componentes da incerteza da atividade lipásica

Figura 5.1 - Curva de calibração para a pipeta graduada de $1 \mathrm{~mL} \mathrm{n}^{\circ}$ de identificação 8, certificado VOL- 013/06

Figura 5.2 - Esquema para determinação do desvio padrão da quantificação do crescimento celular. (a) desvio padrão do instrumento, (b) desvio padrão da diluição

Figura 5.3 - Cultivo de Y. lipolytica em meio contendo 5,5\% de óleo de oliva, $0,7 \%$ de peptona e 2,2\% de inóculo (Experimento 1). (a) atividade lipásica, (b) crescimento celular

Figura 5.4 - Cultivo de Y. lipolytica em meio contendo 5,5\% de óleo de oliva, 0,2\% de peptona e 10\% de inóculo (Experimento 2). (a) atividade lipásica, (b) crescimento celular Figura 5.5 - Cultivo de Y. lipolytica em meio contendo 5,5\% de óleo de oliva, 1,2\% de peptona e 0,5\% de inóculo (Experimento 3). (a) atividade lipásica, (b) crescimento celular 
Figura 5.6 - Cultivo de Y. lipolytica em meio contendo $0,5 \%$ de óleo de oliva, 1,2\% de peptona e 2,2\% de inóculo (Experimento 4). (a) atividade lipásica, (b) crescimento celular Figura 5.7 - Cultivo de Y. lipolytica em meio contendo 5,5\% de óleo 93 de oliva, $0,2 \%$ de peptona e $0,5 \%$ de inóculo (Experimento 5). (a) atividade lipásica, (b) crescimento celular Figura 5.8 - Cultivo de Y. lipolytica em meio contendo 5,5\% de óleo 94 de oliva, 1,2\% de peptona e $10 \%$ de inóculo (Experimento 6). (a) atividade lipásica, (b) crescimento celular Figura 5.9 - Cultivo de Y. lipolytica em meio contendo 0,5\% de óleo 95 de oliva, $0,2 \%$ de peptona e $10 \%$ de inóculo (Experimento 7 ). (a) atividade lipásica, (b) crescimento celular Figura 5.10 - Cultivo de $Y$. lipolytica em meio contendo $0,5 \%$ de óleo 96 de oliva, $0,2 \%$ de peptona e $0,5 \%$ de inóculo (Experimento 8). (a) atividade lipásica, (b) crescimento celular Figura 5.11 - Cultivo de Y. lipolytica em meio contendo 0,5\% de óleo 97 de oliva, $0,7 \%$ de peptona e 10\% de inóculo (Experimento 9). (a) atividade lipásica, (b) crescimento celular Figura 5.12 - Cultivo de $Y$. lipolytica em meio contendo 3,0\% de óleo 98 de oliva, $0,82 \%$ de peptona e $4,6 \%$ de inóculo (Experimento 10). (a) atividade lipásica, (b) crescimento celular Figura 5.13 - Curvas de nível da superfície de resposta da atividade 105 lipásica máxima contra a concentração de carbono $\left(\xi_{1}\right)$ e nitrogênio $\left(\xi_{2}\right)$ com a concentração de inóculo fixa em $0,5 \mathrm{mg} / \mathrm{mL}$ Figura 5.14 - Curvas de nível da superfície de resposta da 106 atividade lipásica máxima contra a concentração de carbono $\left(\xi_{1}\right)$ e nitrogênio $\left(\xi_{2}\right)$ com a concentração de inóculo fixa em 2,2 mg/mL Figura 5.15 - Curvas de nível da superfície de resposta da 106 atividade lipásica máxima contra a concentração de carbono $\left(\xi_{1}\right)$ e nitrogênio $\left(\xi_{2}\right)$ com a concentração de inóculo fixa em $10 \mathrm{mg} / \mathrm{mL}$ Figura 9.1 - Certificado de calibração VOL- 004/06 para o balão 125 volumétrico de $25 \mathrm{~mL} \mathrm{n}^{\circ}$ de identificação 3 
Figura 9.2 - Certificado de calibração VOL- 007/06 para o balão 126 volumétrico de $50 \mathrm{~mL} \mathrm{n}{ }^{\circ}$ de identificação 1

Figura 9.3 - Certificado de calibração VOL- 003/06 para o balão 127 volumétrico de $50 \mathrm{~mL} \mathrm{n}^{\circ}$ de identificação 2

Figura 9.4 - Certificado de calibração VOL- 005/06 para o balão 128 volumétrico de $50 \mathrm{~mL} \mathrm{n}^{\circ}$ de identificação 3

Figura 9.5 - Certificado de calibração VOL- 008/06 para o balão 129 volumétrico de $50 \mathrm{~mL} \mathrm{n}{ }^{\circ}$ de identificação 4

Figura 9.6 - Certificado de calibração VOL- 006/06 para o balão 130 volumétrico de $50 \mathrm{~mL} \mathrm{n}^{\circ}$ de identificação 5

Figura 9.7 - Certificado de calibração VOL- 011/06 para o balão 131 volumétrico de $100 \mathrm{~mL} \mathrm{n}^{\circ}$ de identificação 1

Figura 9.8 - Certificado de calibração VOL- 012/06 para o balão 132 volumétrico de $100 \mathrm{~mL} \mathrm{n}^{\circ}$ de identificação 3

Figura 9.9 - Certificado de calibração VOL- 010/06 para o balão 133 volumétrico de $100 \mathrm{~mL} \mathrm{n}^{\circ}$ de identificação 4

Figura 9.10 - Certificado de calibração VOL- 024/06 para o balão 134 volumétrico de $250 \mathrm{~mL} \mathrm{n}^{\circ}$ de identificação 3

Figura 9.11 - Certificado de calibração VOL- 009/06 para o balão 135 volumétrico de $1000 \mathrm{~mL} \mathrm{n}^{\circ}$ de identificação 2

Figura 9.12 - Certificado de calibração VOL- 094/06 para a pipeta 136 graduada de $1 \mathrm{~mL} \mathrm{n}^{\circ}$ de identificação 3

Figura 9.13 - Certificado de calibração VOL- 020/06 para a pipeta 137 graduada de $1 \mathrm{~mL} \mathrm{n}^{\circ}$ de identificação 5

Figura 9.14 - Certificado de calibração VOL-014/06 para a pipeta 138 graduada de $1 \mathrm{~mL} \mathrm{n}^{\circ}$ de identificação 6

Figura 9.15 - Certificado de calibração VOL- 013/06 para a pipeta 139 graduada de $1 \mathrm{~mL} \mathrm{n}^{\circ}$ de identificação 8

Figura 9.16 - Certificado de calibração VOL- 017/06 para a pipeta 140 graduada de $1 \mathrm{~mL} \mathrm{n}^{\circ}$ de identificação 9

Figura 9.17 - Certificado de calibração VOL- 016/06 para a pipeta 141 graduada de $1 \mathrm{~mL} \mathrm{n}^{\circ}$ de identificação 10

Figura 9.18 - Certificado de calibração VOL- 022/06 para a pipeta 142 graduada de $2 \mathrm{~mL} \mathrm{n}^{\circ}$ de identificação 3 
Figura 9.19 - Certificado de calibração VOL- 093/06 para a pipeta 143 graduada de $2 \mathrm{~mL} \mathrm{n}^{0}$ de identificação 5

Figura 9.20 - Certificado de calibração VOL- 021/06 para a pipeta 144 graduada de $2 \mathrm{~mL} \mathrm{n}{ }^{\circ}$ de identificação 6

Figura 9.21 - Certificado de calibração VOL-018/06 para a pipeta 145 graduada de $5 \mathrm{~mL} \mathrm{n}{ }^{\circ}$ de identificação 8

Figura 9.22 - Certificado de calibração VOL- 092/06 para a pipeta 146 graduada de $5 \mathrm{~mL} \mathrm{n}^{0}$ de identificação 9

Figura 9.23 - Certificado de calibração VOL- 015/06 para a pipeta 147 graduada de $10 \mathrm{~mL} \mathrm{n}^{\circ}$ de identificação 5

Figura 9.24 - Certificado de calibração VOL- 019/06 para a pipeta 148 graduada de $10 \mathrm{~mL} \mathrm{n}^{\circ}$ de identificação 7

Figura 9.25 - Certificado de calibração VOL- 095/06 para a pipeta 149 graduada de $20 \mathrm{~mL} \mathrm{n}^{\circ}$ de identificação 3

Figura 9.26 - Certificado de calibração VOL- 023/06 para a bureta 150 de $25 \mathrm{~mL} \mathrm{n}^{\circ}$ de identificação 1

Figura 9.27 - Curva de calibração para a pipeta graduada de $1 \mathrm{~mL} 156$ $n^{\circ}$ de identificação 3, certificado VOL- 094/06

Figura 9.28 - Curva de calibração para a pipeta graduada de $1 \mathrm{~mL} 156$ $\mathrm{n}^{\circ}$ de identificação 5, certificado VOL- 020/06

Figura 9.29 - Curva de calibração para a pipeta graduada de $1 \mathrm{~mL} 157$ $\mathrm{n}^{\circ}$ de identificação 6, certificado VOL- 014/06

Figura 9.30 - Curva de calibração para a pipeta graduada de $1 \mathrm{~mL} 157$ $\mathrm{n}^{\circ}$ de identificação 9, certificado VOL- 017/06

Figura 9.31 - Curva de calibração para a pipeta graduada de $1 \mathrm{~mL} 158$ $n^{\circ}$ de identificação 10, certificado VOL- 016/06

Figura 9.32 - Curva de calibração para a pipeta graduada de $2 \mathrm{~mL} 158$ $n^{0}$ de identificação 3, certificado VOL- 022/06

Figura 9.33 - Curva de calibração para a pipeta graduada de 2 mL 159 $\mathrm{n}^{\circ}$ de identificação 5, certificado VOL- 093/06

Figura 9.34 - Curva de calibração para a pipeta graduada de 2 mL 159 $\mathrm{n}^{\circ}$ de identificação 6, certificado VOL- 021/06

Figura 9.35 - Curva de calibração para a pipeta graduada de $5 \mathrm{~mL} 160$ $\mathrm{n}^{\circ}$ de identificação 8, certificado VOL- 018/06 
Figura 9.36 - Curva de calibração para a pipeta graduada de $5 \mathrm{~mL} \quad 160$ $\mathrm{n}^{\circ}$ de identificação 9, certificado VOL- 092/06

Figura 9.37 - Curva de calibração para a pipeta graduada de $10 \mathrm{~mL} \quad 161$ $n^{\circ}$ de identificação 5, certificado VOL- 015/06

Figura 9.38 - Curva de calibração para a pipeta graduada de $10 \mathrm{~mL} \quad 161$ $n^{\circ}$ de identificação 7, certificado VOL- 019/06

Figura 9.39 - Curva de calibração para a pipeta graduada de $20 \mathrm{~mL} 162$ $\mathrm{n}^{\circ}$ de identificação 3, certificado VOL- 095/06

Figura 9.40 - Curva de calibração para a bureta graduada de $25 \mathrm{~mL} 162$ $n^{0}$ de identificação 1, certificado VOL- 023/06 


\section{Lista de Tabelas}

Tabela 2.1 - Algumas aplicações comerciais de lipases microbianas 47

Tabela 2.2 - Algumas lipases microbianas disponíveis 52 comercialmente

Tabela 2.3 - Métodos empregados para purificação e características de algumas lipases microbianas

Tabela 2.4 - Métodos empregados para detecção da atividade lipásica

Tabela 4.1 - Níveis empregados para os fatores $\mathrm{C}, \mathrm{N}$ e $\mathrm{I}_{0}$

Tabela 4.2 - Planejamento dos experimentos através do método D-optimal

Tabela 4.3 - Composição dos meios líquidos utilizados para produção de lipases

Tabela 4.4 - Concentração inicial de células para cada experimento

Tabela 4.5 - Incertezas expandidas $(U)$ de cada elemento do biftalato de potássio

Tabela 5.1 - Resultado da estimativa do desvio padrão para a quantificação do crescimento celular

Tabela 5.2 - Resultados da determinação do número de repetições necessárias para a determinação da atividade lipásica

Tabela 5.3 - Condições de cultivo e resultados obtidos para cada experimento

Tabela 5.4 - Efeito da concentração de óleo de oliva

Tabela 5.5 - Efeito da concentração de peptona

Tabela 5.6 - Efeito da concentração de inóculo

Tabela 5.7 - Valores dos resíduos para todos os experimentos $\quad 105$

Tabela 5.8 - Parâmetros de produção de lipases por células de 108 Yarrowia lipolytica

Tabela 5.9 - Incertezas expandidas estimadas para a atividade 109 lipásica 